\title{
Protective Effect of CpG- Oligodeoxynucleotides Against Low- and High-LET Irradiation
}

\author{
Chao Zhang ${ }^{b}$ Min Zheng ${ }^{c}$ Xiang-Hui Zhub Sha Lib Jin Nia Bai-Long Lia Hu Liu ${ }^{a}$ \\ Fu Gao Jian-Ming Cai ${ }^{a}$ \\ aSection of Radiation Medicine, Department of Naval Medicine, Second Military Medical University, \\ Shanghai, 'Department of Radiotherapy, Lanzhou General Hospital of Lanzhou Military Region, \\ Lanzhou, 'Department of Thoracic Surgery, Shanghai Tongren Hospital, Shanghai, China
}

\author{
Key Words \\ CpG-ODNs • Irradiation • Carbon beam • High-LET
}

\begin{abstract}
Background/Aims: CpG-oligodeoxynucleotides (ODNs) are synthetic DNA sequences containing unmethylated cytosine-guanine motifs with potent immunomodulatory effects. Previous reports showed a powerful protective effect of CpG-ODN against the damage induced by low-LET $\gamma$-rays. In this study, we explored whether CpG-ODN also protects against the damage induced by high-LET irradiation. Parallel experiments were performed with lowLET irradiation. Methods: RAW264.7 cells were incubated with $1 \mu \mathrm{M}$ of CpG-ODN after $\gamma$-ray or carbon-beam irradiation. Cell death was then measured by PI/DAPI double staining, cell survival was assessed by colony-formation assays, DNA damage was evaluated by comet assays, cell cycle was monitored by flow cytometry, and the levels of apoptosis-related proteins were detected by western blots. Results: When irradiated cells were treated with the CpG-ODN, cell viability decreased, cell survival increased, DNA damage and $G_{2} / M-p h a s e$ arrest were ameliorated, and apoptosis was inhibited. Conclusions: The CpG-ODN showed protective effects against low-LET $\gamma$-ray and high-LET carbon-beam irradiation. These effects might be associated with the repair of DNA damage and inhibition of apoptosis.
\end{abstract}




\section{Introduction}

Qualitatively high-linear energy transfer (LET) radiation, such as heavy ions, $\alpha$-particles and neutrons, is densely ionizing. Due to its physical and radiobiological properties, highLET radiation is of special interest for tumor therapy. Recent and proposed radiation therapy strategies use carbon ions to effectively treat malignant tumors [1-3]. However, the absorbed dose delivered by high-LET heavy ion irradiation undergoes penetration and then higher-energy deposition in the bodies of patients. The irradiation not only destroys tumor tissue but can also lead to serious damage to normal cells surrounding the tumor [4]. It was reported that high-LET heavy ion irradiation is much more damaging to normal cells than low-LET irradiation, which causes immune cell death, immunosuppression, and an increased risk of opportunistic infections during tumor radiotherapy [5]. In addition to the emerging side effects that occur during radiotherapy, high-LET heavy ion irradiation also constitutes a major health risk for crews aboard air- or spacecraft; outside the protective shielding of the earth's atmosphere, crews are exposed to increased levels of high-LET heavy ion radiation from space [6]. It is estimated that during a 3-year space mission, a significant number of cells in the body will be exposed to high-LET heavy ion radiation, and the total radiation dose that crews may receive could reach 3 Gy [7]. Although high-LET heavy ion irradiation can affect many physiological systems, immune dysfunction, with its potentially serious consequences, is a paramount concern. It is undoubtedly important to find methods to protect immune cells from damage induced by high-LET heavy ion irradiation.

CpG-oligodeoxynucleotides (ODNs), which are synthetic analogs of bacterial DNA, can be generated containing specific unmethylated cytosine-guanine motifs [8]. The signaling pathway is triggered when CpG-ODNs interact with Toll-like receptor 9 (TLR9), which then recruits myeloid differentiation factor 88 (MyD88), IL-1R-associated kinase (IRAK), and tumor necrosis factor receptor-associated factor 6 (TRAF6), culminating in the activation of NF- $\kappa$ B [9-11]. Previous work determined that CpG-ODNs had a protective effect against lowLET irradiation both in vitro and in vivo. Indeed, Sohn et al. demonstrated that CpG-ODNs inhibited $\gamma$-rays irradiation-induced immune cell death [12]. Studies from our laboratory suggested that CpG-ODNs ameliorate the damage to hematopoietic cells and intestinal crypt cells after $\gamma$-ray irradiation [13-15]. We speculated that CpG-ODNs would also have the protective effect against high-LET irradiation. To the best of our knowledge, the present study is the first to investigate the effect of CpG-ODNs against the damage induced by highLET carbon beams and to compare this effect with that of low-LET $\gamma$-rays.

\section{Materials and Methods}

Agents

The CpG-ODN was synthesized at Shanghai Sangon Biological Engineering Technology Services Co. Ltd.

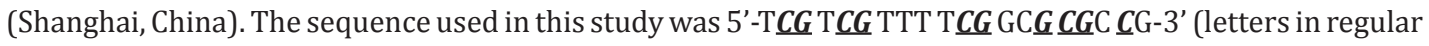
type represent phosphorothioates; bold and italic letters represent phosphodiesters) [16]. Endotoxins were removed. The compound was diluted with phosphate-buffered saline (PBS) to a concentration of $100 \mu \mathrm{M}$ and stored at $4^{\circ} \mathrm{C}$.

\section{Cell culture and treatments}

The mouse macrophage cell line RAW264.7 was obtained from the American Type Culture Collection (ATCC, Manassas, USA). Cells were cultured in Dulbecco's modified Eagle's medium (DMEM) supplemented with $10 \%$ fetal bovine serum and maintained at $37{ }^{\circ} \mathrm{C}$ with $5 \% \mathrm{CO}_{2}$ and $95 \%$ humidity. All culture reagents were purchased from HyClone (Pennsylvania, USA). Exponentially growing cells were harvested and seeded in $25 \mathrm{~cm}^{2}$ plastic flasks (Corning, New York, USA) $8 \mathrm{~h}$ before irradiation. Viability, which was assayed using trypan blue dye exclusion, was typically greater than $95 \%$. After plating, irradiated cells were treated with or without $1 \mu \mathrm{M} \mathrm{CpG-ODN}$ for $3 \mathrm{~h}$. 
Zhang et al.: The Radioprotective Effect of CpG-ODN

\section{Irradiation}

$\gamma$-ray irradiation was performed at the radiation facility of Second Military Medical University (SMMU, Shanghai, China). Cells were irradiated with ${ }^{60} \mathrm{Co} \gamma$-radiation at $1.0 \mathrm{~Gy} / \mathrm{min}$. Carbon-beam radiation was supplied by the Heavy Ion Research Facility in Lanzhou (HIRFL, Institute of Modern Physics, Chinese Academy of Sciences, Lanzhou, China). A carbon beam with an initial energy of $290 \mathrm{MeV} / \mathrm{n}$ was generated, and modular films were used to achieve a LET value of $100 \mathrm{keV} / \mu \mathrm{m}$. Cells were irradiated at room temperature. The control group was treated with the same protocol, except the irradiation was excluded.

\section{MTT assays}

The toxicity of the CpG-ODN on RAW264.7 cells was tested by MTT assay. Cells $\left(1.0 \times 10^{4}\right.$ cells/ well) were seeded in 96-well plates and incubated with varying final concentrations of CpG-ODN for $24 \mathrm{~h}$. Subsequently, $20 \mu \mathrm{l}$ of 3-(4,5-dimethylthiazol-2-yl)-2,5-diphenyltetrazolium bromide (MTT) was added to each well and incubated for $2 \mathrm{~h}$. The medium was then replaced with $200 \mu \mathrm{l}$ of dimethyl sulfoxide (DMSO). The absorbance of each well at $490 \mathrm{~nm}$ was measured spectrophotometrically using a 96-well plate reader. The absorbance of empty wells was used as a control. The MTT assay was repeated three times with six replicates per experiment. The data were analyzed using Microsoft Excel 2010. The half maximal inhibitory concentration $\left(\mathrm{IC}_{50}\right)$ was calculated by fitting a linear-quadratic function.

\section{DAPI/PI double staining}

Cell death was measured using propidium iodide (PI) and 4,6-diamidino-2-phenylindole (DAPI) double staining. Cells were stained with PI and DAPI and then manually counted under a fluorescent microscope (Nikon, Tokyo, Japan) $24 \mathrm{~h}$ after irradiation. Cellular states were recorded: all cells were stained blue with DAPI under UV fluorescence, and dead cells were stained red with PI under green fluorescence. The analysis was conducted in a blind manner, i.e., the observer had no knowledge of the identity of the samples. The median lethal dose $\left(\mathrm{LD}_{50}\right)$ and the dose-modifying factor (DMF) were calculated.

\section{Colony-formation assays and dose-survival fractions}

Cell survival was assessed by colony-formation assays. Cells were counted using a cell counter analyzer system (CASY), diluted by geometric proportion, and seeded in flasks to provide $50-800 \mathrm{cells} / \mathrm{ml}$. Increasing numbers of cells were exposed to increasing doses of radiation: a 50 cells $/ \mathrm{ml}$ solution was exposed to 0 Gy; a 100 cells $/ \mathrm{ml}$ solution was exposed to $0.5 \mathrm{~Gy}$; a 200 cells $/ \mathrm{ml}$ solution was exposed to $2 \mathrm{~Gy}$; a $400 \mathrm{cells} / \mathrm{ml}$ solution was exposed to $4 \mathrm{~Gy}$; and a solution of 800 cells $/ \mathrm{ml}$ was exposed to $6 \mathrm{~Gy}$ ). The irradiated cells were then incubated for approximately 14 days, fixed with methanol:acetic acid (9:1 v/v) for 30 min and stained with $5 \mu \mathrm{M}$ DAPI. The bottom of the flask was divided into 9 areas, and the number of colonies (more than 50 cells) was counted in each area under a fluorescence microscopy $(10 \times)$. The survival fraction $=(\mathrm{N} 1 / \mathrm{n} 1) /$ (N2/n2) N1: the number of cells forming colonies after irradiation; n1: the number of seeded cells after irradiation; N2: the number of cells forming colonies in the control group; $\mathrm{n} 2$ : the number of seeded cells in the control group). A modified single-hit multi-target model was established to analyze the survival fraction. The formula used was $\mathrm{S}=n e^{-k D}$, where the survival fraction is expressed in terms of the four parameters $D_{q^{\prime}}$ $D_{0}, D_{37}$ and $n . \mathrm{D}_{\mathrm{q}}$ (the size or width of the shoulder of the curve, $\mathrm{D}_{\mathrm{q}}=\operatorname{In} n / k$ ) represents the minimum radiation dose that inevitably leads to cell death, $D_{0}$ (the slope of the curve, $\mathrm{D}_{0}=1 / k$ ) represents the mean lethal dose, $D_{37}$ represents the dose required for $37 \%$ survival, and $n$ is the extrapolation number [17].

\section{Comet assays (single-cell gel electrophoresis)}

DNA damage was evaluated using the comet assay. Cells were incubated for $24 \mathrm{~h}$ after irradiation with 6 Gy. Conventional microscope slides were covered with a solution of $85 \mu$ of $1 \%$ normal-melting-point agarose (NMP) and allowed to dry on a flat surface at room temperature. Ten microliters of cell suspension $\left(2.5 \times 10^{5}\right.$ cells $\left./ \mathrm{ml}\right)$ was gently mixed with $75 \mu \mathrm{l}$ of $0.5 \%(\mathrm{w} / \mathrm{v})$ low-melting-point agarose (LMP). The suspension was rapidly layered onto the slides precoated with $1 \%$ NMP and covered with a coverslip. After removing the coverslip, cells were immersed into a freshly made lysis solution at $4{ }^{\circ} \mathrm{C}$ for $1 \mathrm{~h}$. The slides were placed into the electrophoresis tank. Electrophoresis $(30 \mathrm{~V}, 300 \mathrm{~mA})$ was conducted for $15 \mathrm{~min}$ at $4{ }^{\circ} \mathrm{C}$, and the slides were stained with PI for $20 \mathrm{~min}$ and observed under a fluorescence microscope [18, 19]. 
Fig. 1. Cytotoxicity effect of CpG-ODN on cell. RAW264.7 cells were incubated with various final dose of CpG-ODN. MTT assay was used to assesse viability of cells after $24 \mathrm{~h}$. The $\mathrm{IC}_{50}$ values of $61.4 \mu \mathrm{M}$ were calculated. (Data are represented by the mean \pm SEM from 3 independent experiments, ${ }^{*} p<0.05$ for significant differences between normal group and other concentration group).

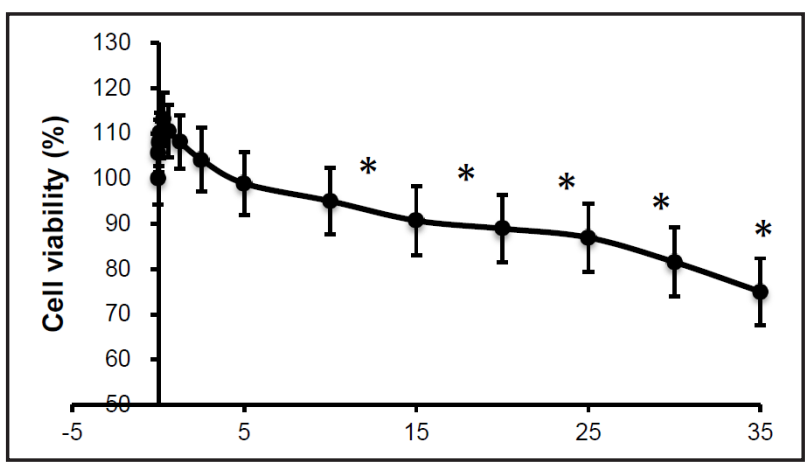

Cell cycle analysis

The cell cycle was monitored using a flow cytometer. Irradiated cells were incubated for $12 \mathrm{~h}$ and then trypsinized, rinsed, resuspended in PBS, and fixed with ice-cold $70 \%$ ethanol for least $3 \mathrm{~h}$. The fixed cells were rinsed again with PBS and stained with $50 \mu \mathrm{g} / \mathrm{ml}$ PI. A flow cytometer (Beckman, California, USA) was used to analyze the cell cycle phase of the cells.

\section{Western blots}

The expression of apoptosis-related proteins was detected by western blotting. Cells were incubated for $12 \mathrm{~h}$ after irradiation and then harvested, washed with cold PBS, lysed with mammalian protein extraction reagent (Thermo, Pennsylvania, USA) for $30 \mathrm{~min}$ on ice, and centrifuged at $14,000 \times g$ for $10 \mathrm{~min}$ at $4^{\circ} \mathrm{C}$. The concentration of cleared protein supernatants was evaluated using the Bradford method. Proteins were resolved by $12 \%$ SDS-polyacrylamide gel electrophoresis and electrotransferred to nitrocellulose membranes. Membranes were blocked with 5 \% nonfat milk in TBS containing $0.1 \%$ Tween-20 (TBST) for $1 \mathrm{~h}$ at room temperature. Afterwards, the blots were incubated in primary antibody at $4{ }^{\circ} \mathrm{C}$ overnight. The membranes were then incubated with horseradish peroxidase-conjugated secondary antibody for $3 \mathrm{~h}$ at room temperature. For densitometry analysis, an enhanced chemiluminescence detection system (Gene Company, Hong Kong, China) was used to measure specific protein bands, and band densities were quantified using the Gene Tools software.

\section{Statistical analysis}

Data are presented as means \pm standard errors of the means (means \pm SEMs). The significance of differences between groups was determined by Student's $t$-test. The parameter values (including $\mathrm{D}_{\mathrm{q}}, \mathrm{D}_{0}, \mathrm{D}_{37}$ ) were determined by corresponding regression analysis. The software analysis program SPSS 13.0 (Release 12.0 K; SPSS Inc., Chicago, USA) was used. All $p$ values were obtained using two-tailed tests. $P<0.05$ was considered to be statistically significant.

\section{Results}

Cytotoxic effect of the CpG-ODN on RAW 264.7 cells

The cytotoxic effect of the CpG-ODN on RAW264.7 cells was assessed by MTT assay. The result showed that there was no significant change in cell viability in cells treated with a final concentration of $15.0 \mu \mathrm{M}$ CpG-ODN compared with the control cells. However, when the final concentration of CpG-ODN was higher than $15.0 \mu \mathrm{M}$, cell viability was significantly decreased in a dose-dependent manner, with an $\mathrm{IC}_{50}$ value of $61.4 \mu \mathrm{M}$ (Fig. 1). For all further experiments, a final concentration of $1.0 \mu \mathrm{M} \mathrm{CpG-ODN}$ was used. These results suggested that the CpG-ODN had little cytotoxic effect on RAW264.7 cells.

\section{Effect of CpG-ODN on cell death after irradiation}

To examine the protective effect of the CpG-ODN against cellular damage after $\gamma$-ray or carbon-beam irradiation, the viability of the cells was measured by PI/DAPI double staining. As shown in Fig. 2A, $\gamma$-ray and carbon-beam irradiation resulted in a large amount of cell death. Compared with the viability of cells exposed to $\gamma$-ray radiation, a clear increase in cell 
Fig. 2. Effect of CpG-ODN on cell death after irradiation. RAW264.7 cells were treated with or without $1 \mu \mathrm{M} \mathrm{CpG-}$ ODN after 2 Gy, 4 Gy and 6 Gy of $\gamma$-ray or carbon-beam irradiation. (A) Death cell was measured by PI/DAPI double staining at $24 \mathrm{~h}$ after irradiation and photographed under a fluorescent microscopy; (B) the mortality of cell was quantified by manually counting; (C) The values of $\mathrm{LD}_{50}$ and DMF were calculated by fitting linear-quadratic function. (Data are represented by the mean \pm SEM from 3 independent experiments, $* p<0.05$ for significant differences between $\gamma$-ray plus CpG-ODN group and $\gamma$-ray control group; ${ }^{*} \mathrm{p}<0.05$ for significant differences between carbon-beam plus CpG-ODN group and carbon-beam control group).

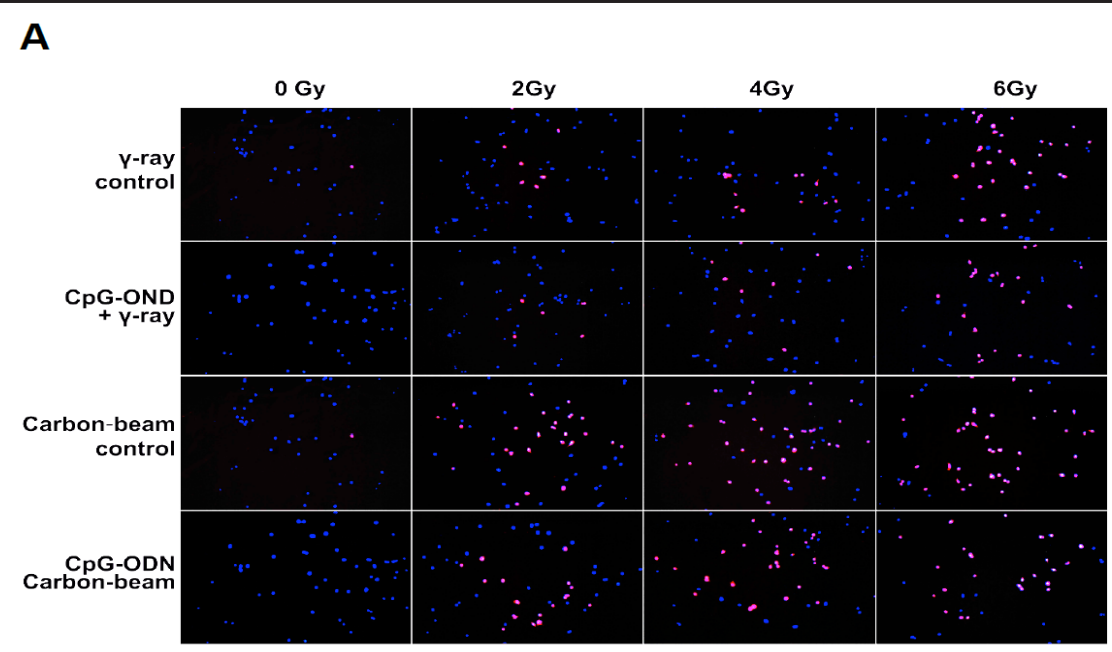

B

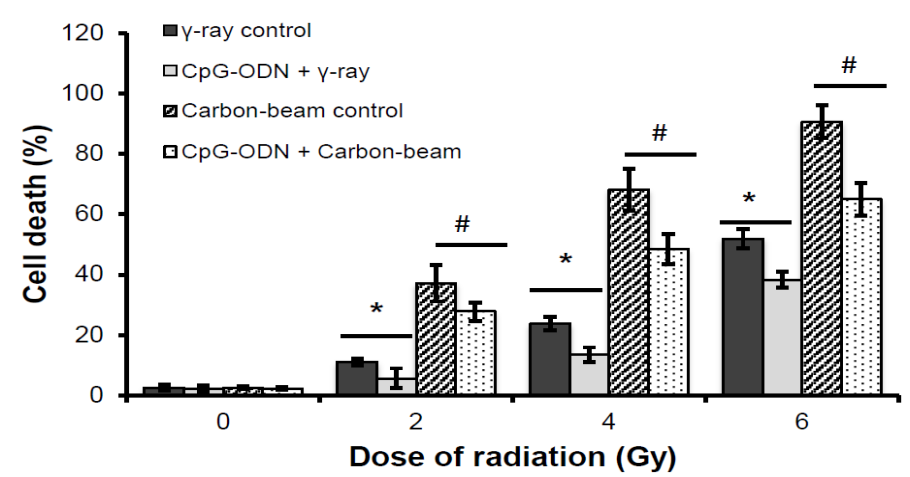

C

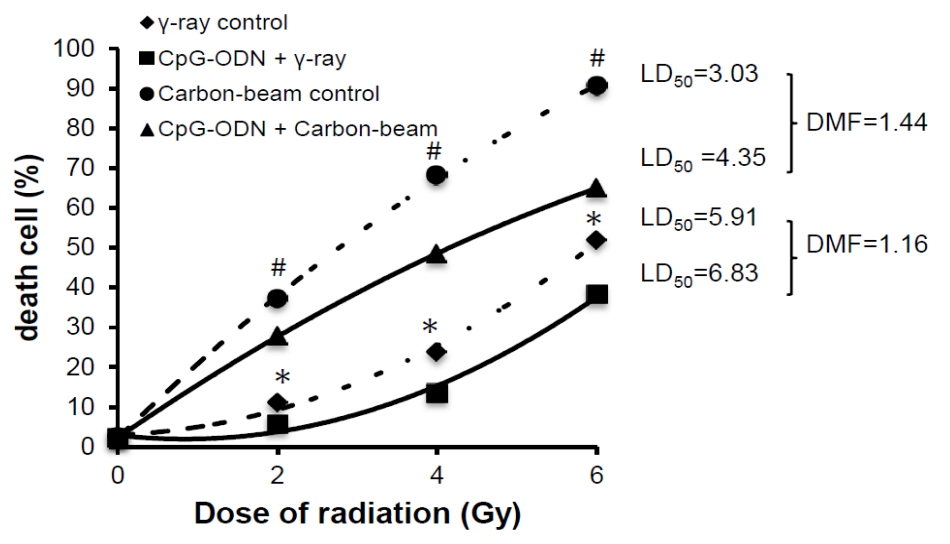

death was observed in cells exposed to carbon-beam radiation. However, CpG-ODN treatment reduced cell death. For $\gamma$-ray radiation, the percentage of dead cells decreased from $11.1 \%$, $23.8 \%$ and $51.9 \%$ in the control cells to $5.7 \%, 13.5 \%$ and $38.3 \%$ in the CpG-ODN-treated cells after exposure to $2 \mathrm{~Gy}, 4$ Gy and 6 Gy of $\gamma$-ray radiation, respectively (Fig. 2B). The $\mathrm{LD}_{50}$ increased from 5.91 Gy to 6.83 Gy after treatment, and the DMF value was 1.16 . For carbonbeam radiation, the percentage of dead cells decreased from $37.1 \%, 68.2 \%$, and $90.6 \%$ in the control cells to $27.8 \%, 48.5 \%$ and $65.0 \%$ in the CpG-ODN-treated cells after exposure to 2 Gy, 4 Gy and 6 Gy of carbon-beam radiation, respectively (Fig. 2B). The $\mathrm{LD}_{50}$ value increased 
Fig. 3. Effect of CpG-ODN on cell survival after irradiation. RAW264.7 cells were treated with or without $1 \mu \mathrm{M} \mathrm{CpG-ODN}$ after 0.5 Gy, 2 Gy, 4 Gy and 6 Gy of $\gamma$-ray or carbon-beam irradiation. Survival fraction was established by colony forming assay. Three parameters are listed in Table 1. (Data are represented by the mean \pm SEM from 3 independent experiments, ${ }^{*} p<0.05$ for significant differences between $\gamma$-ray plus CpG-ODN group and $\gamma$-ray control group; ${ }^{\#} p<0.05$ for significant differences between carbon-beam plus CpG-ODN group and carbon-beam control group).

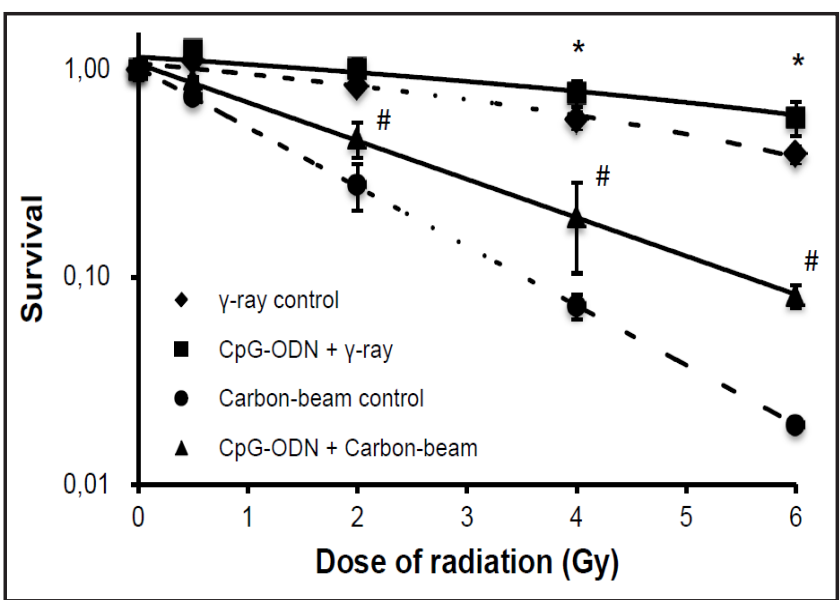

Table 1. Parameters and of survival curves obtained with a modified model

\begin{tabular}{lcccc}
\hline & $n$ & $D_{q}$ & $D_{0}$ & $D_{37}$ \\
\hline$\gamma$-ray control & 1.215 & 1.030 & 5.291 & 6.291 \\
CpG-ODN + $\gamma$-ray & 1.327 & 2.080 & 7.353 & 9.255 \\
Carbon-beam control & 1.024 & 0.036 & 1.511 & 1.538 \\
CpG-ODN + Carbon-beam & 1.118 & 0.255 & 2.281 & 2.525 \\
\hline
\end{tabular}

from 3.03 Gy to 4.35 Gy after CpG-ODN treatment, and the DMF value was 1.44. These results suggested that the CpG-ODN reduced cell death after $\gamma$-ray and carbon-beam irradiation.

\section{Effect of CpG-ODN on cell survival after irradiation}

Next, the effect of the CpG-ODN on cell survival after $\gamma$-ray and carbon-beam irradiation was described by colony-formation assays, and the survival fraction $\left(\mathrm{S}=n e^{-k \mathrm{D}}\right)$ was established. The parameters obtained are listed in Table 1. As shown in Fig. 3, $\gamma$-ray and carbon-beam irradiation resulted in a dose-dependent decrease in the number of surviving cells. Survival curves were characterized by an initial shoulder region at low doses of radiation that was followed by an exponential decrease in survival. The survival curve of cells exposed to $\gamma$-rays showed a wider shoulder $\left(D_{q}=1.030 \mathrm{~Gy}\right)$, and the dose required for $37 \%$ survival $\left(D_{37}\right)$ was $6.29 \mathrm{~Gy}$. In contrast, the survival curve of cells treated with carbon-beam radiation showed a small shoulder region (Dq=0.036 Gy), and the $\mathrm{D}_{37}$ value was $1.54 \mathrm{~Gy}$, indicating that the relative biological effectiveness (REB) of carbon-beam radiation was 4.08.

For $\gamma$-ray irradiation, CpG-ODN treatment increased the survival fraction. A significant difference in survival was observed after irradiation with either 4 or 6 Gy of $\gamma$-ray radiation. However, when the radiation dose was lower than 2 Gy, there was no significant change in the survival fraction in irradiated cells with or without CpG-ODN treatment, suggesting that the CpG-ODN only altered the slope region of the exponential portion of the survival curves (Fig. 3). As shown in Table 1, the $\mathrm{D}_{0}$ value, which describes the change in the slope region, increased from 5.291 Gy to $7.353 \mathrm{~Gy}$.

The survival fraction was significantly higher in irradiated cells treated with the CpGODN than in irradiated control cells after 0.5 to $6 \mathrm{~Gy}$ of carbon-beam irradiation. The shoulder region and the slope region of the exponential portion of the curve were significantly changed (Fig. 3). As shown in Table 1, the $\mathrm{D}_{\text {v }}$ value increased from 0.036 to $0.255 \mathrm{~Gy}$, and the $\mathrm{D}_{0}$ value increased from 1.511 to $2.281 \mathrm{~Gy}$. These results suggested that CpG-ODN treatment enhanced the survival of the cells after $\gamma$-ray and carbon-beam irradiation.

\section{Effect of CpG-ODN on cellular DNA damage induced by irradiation}

The effect of the CpG-ODN on DNA damage caused by $\gamma$-ray or carbon-beam irradiation was evaluated by comet assays. As shown in Fig. 4A, the cells' fragmented DNA migrated away from the comet head and formed a long tail similar to that of a comet after $\gamma$-ray or 
Fig. 4. Effect of $\mathrm{CpG}$ ODN on cell DNA damage after irradiation. RAW264.7 cells were treated with or without $1 \mu \mathrm{M}$ CpG-ODN after 6 Gy of $\gamma$-ray or carbonbeam irradiation. (A) Degrees of DNA damage were evaluated by comet assay at $24 \mathrm{~h}$ after irradiation and photographed under a fluorescent microscopy. (B) The area of comet tail was quantified. (Data are represented by the mean \pm SEM from 3 independent experiments, ${ }^{*} p<0.05$ for significant differences between $\gamma$-ray plus CpG-ODN group and $\gamma$-ray control group; ${ }^{*} p<0.05$ for significant differences between carbon-beam plus CpG-ODN group and carbon-beam control group).

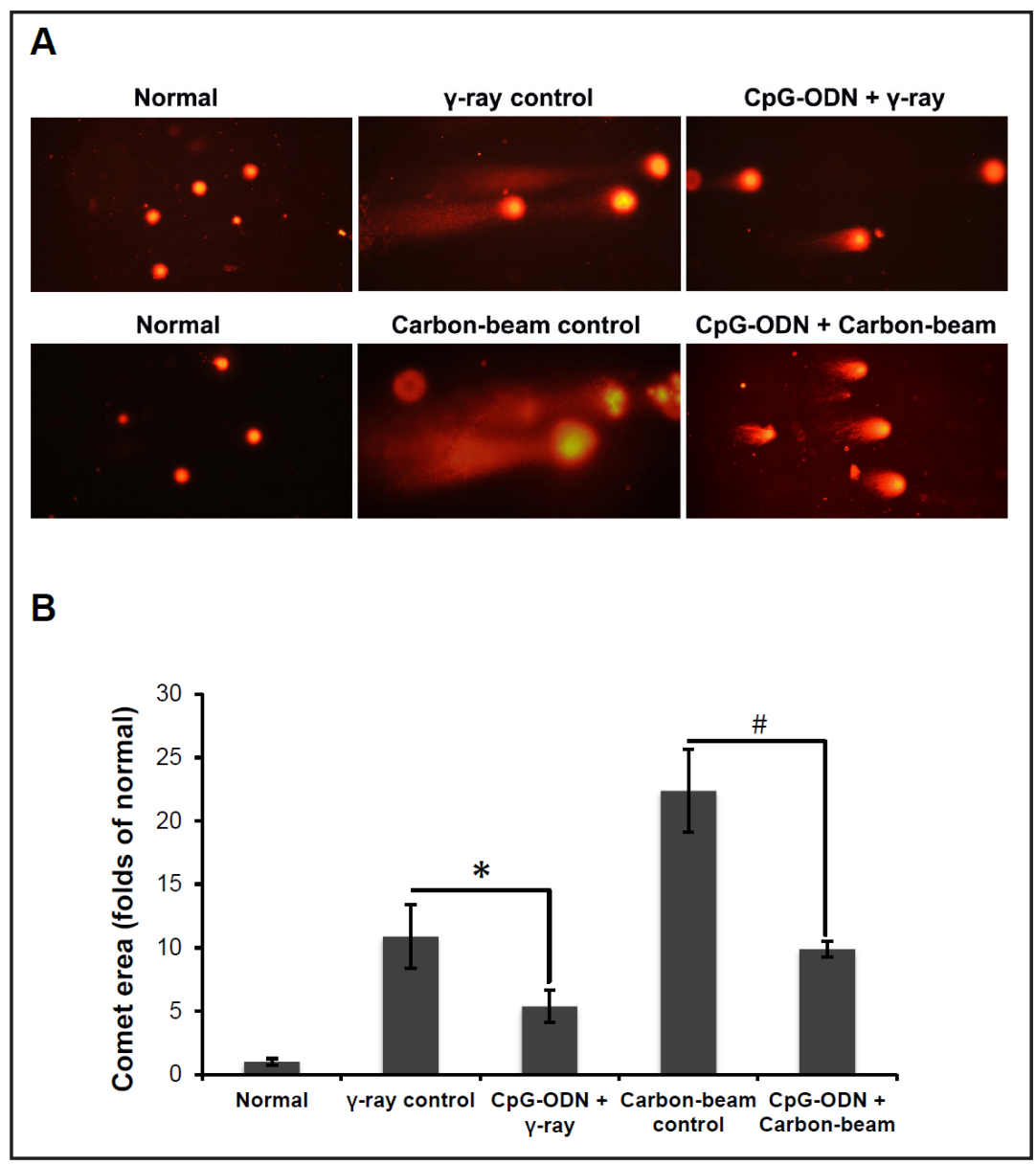

carbon-beam irradiation. However, when irradiated cells were treated with the CpG-ODN, there was a significant difference in the shape of the comet tail. Considerably shorter and narrower comet tails were observed in irradiated cells treated with the CpG-ODN compared with irradiated control cells.

For $\gamma$-ray radiation, the comet tail area decreased by 5 - to 11 -fold after treatment with the CpG-ODN compared with the control. For carbon-beam radiation, the comet tail area was decreased by 10 - to 22 -fold compared with the control (Fig. 5B). This result suggested that the CpG-ODN alleviated the DNA strand breaks induced by $\gamma$-ray or carbon-beam irradiation.

\section{Effect of CpG-ODN on cell-cycle progression after irradiation}

Finally, the effect of CpG-ODN treatment on cell-cycle distribution after $\gamma$-ray or carbonbeam irradiation was analyzed by flow cytometry to determine whether the protection of CpG-ODN treatment was due to the promotion of cell-cycle progression. As shown in Fig. 5A, irradiated cells exhibited $\mathrm{G}_{2} / \mathrm{M}$ phase arrest, as shown by an increased percentage of cells in $\mathrm{G}_{2} / \mathrm{M}$ phase compared with the control cells, but CpG-ODN treatment significantly decreased the fraction of cells in $\mathrm{G}_{2} / \mathrm{M}$ phase after irradiation. For $\gamma$-ray radiation, the percentage was decreased from $63 \%$ to $35 \%$ with CpG-ODN treatment. For carbon-beam radiation, the percentage was decreased from $79 \%$ to $56 \%$ with CpG-ODN treatment. Moreover, compared with the irradiation control group, a significant increase was also observed in the fraction of cells in $G_{0} / G_{1}$ phase in the irradiation group with CpG-ODN treatment. For $\gamma$-ray radiation, the percentage was increased from $23 \%$ to $46 \%$ with CpG-ODN treatment. For carbonbeam radiation, the percentage was increased from $11 \%$ to $29 \%$ with CpG-ODN treatment (Fig. 5B). These results revealed that the CpG-ODN promoted cell-cycle progression after $\gamma$-ray and carbon-beam irradiation. 


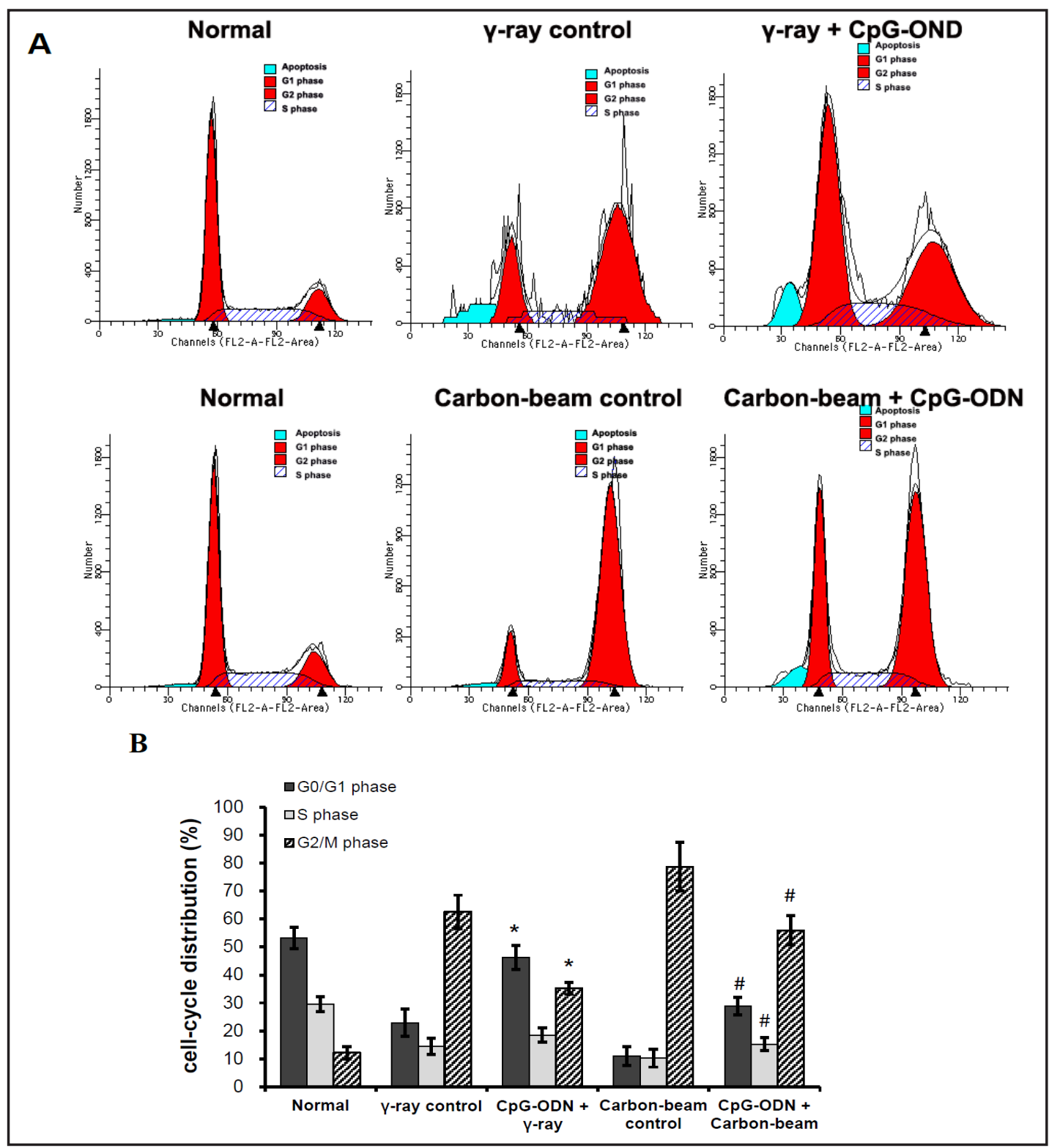

Fig. 5. Effect of CpG-ODN on cell-cycle progression after irradiation. RAW264.7 cells were treated with or without CpG-ODN after 6 Gy of $\gamma$-ray or carbon-beam irradiation. Cell cycle was analyzed by flow cytometry at $12 \mathrm{~h}$ after irradiation. (A) Representative profiles; (B) The percentage of cells in $\mathrm{G}_{0} / \mathrm{G}_{1}, \mathrm{~S}$ and $\mathrm{G}_{2} / \mathrm{M}$ phases. (Data are represented by the mean \pm SEM from 3 independent experiments, ${ }^{*} p<0.05$ for significant differences between $\gamma$-ray plus CpG-ODN group and $\gamma$-ray control group; ${ }^{*} p<0.05$ for significant differences between carbon-beam plus CpG-ODN group and carbon-beam control group).

Effect of CpG-ODN on the expression of apoptosis-related proteins after irradiation

Based on previous results, we investigated the mechanism behind the reduction in DNA damage of RAW267.4 cells by the CpG-ODN after $\gamma$-ray and carbon-beam irradiation. The level of several apoptosis-related proteins, including Bax, Bcl-2, caspase-3 and cleaved caspase-3, was detected by western blot. As shown in Fig. 6A, Bax expression was upregulated, Bcl-2 expression was downregulated, and the ratio of $\mathrm{Bax} / \mathrm{Bcl}-2$, which is considered to be one of the major markers of apoptosis, was also increased [20]. Caspase-3 expression was increased, and cleaved caspase- 3 protein appeared after $\gamma$-ray and carbon-beam irradiation. However, 


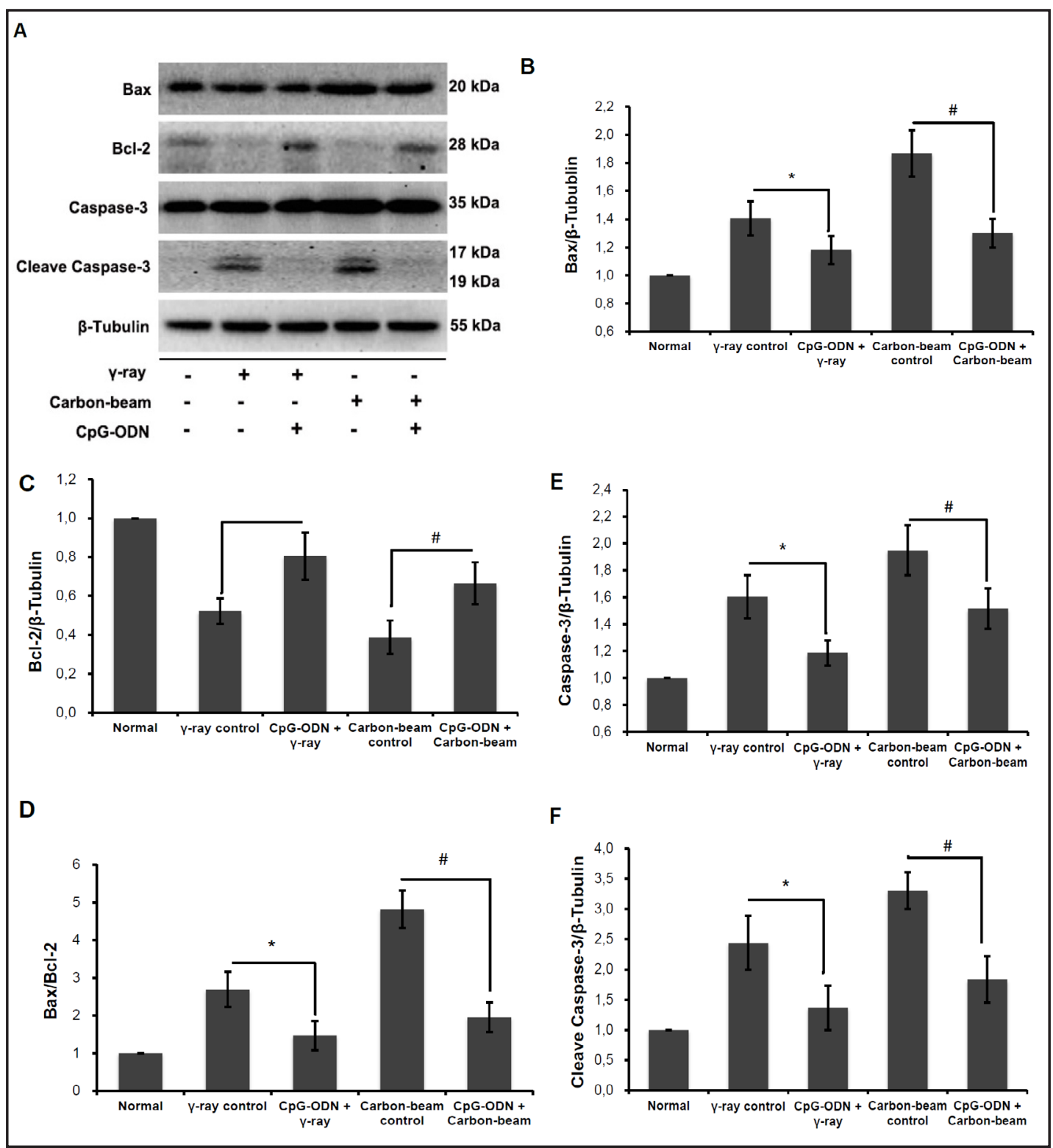

Fig. 6. Effect of CpG-ODN on apoptosis-related proteins expression after irradiation. RAW264.7 cells were treated with or without CpG-ODN after 6 Gy of $\gamma$-ray or carbon-beam irradiation. (A) The expression of apoptosis-related proteins was assessed by western blot assay at $12 \mathrm{~h}$ after irradiation. The expression of Bax (B) and Bcl-2 (C) were quantified by the relative intensity of protein bands, and the ratio of Bax/Bcl-2 was calculated (D); the expression of Caspase-3 and cleaved Caspase-3 proteins was quantified by the by the relative intensity of protein bands. (Data are represented by the mean \pm SEM from 3 independent experiments, ${ }^{*} p<0.05$ for significant differences between $\gamma$-ray plus CpG-ODN group and $\gamma$-ray control group; $\mathrm{p}<0.05$ for significant differences between carbon-beam plus CpG-ODN group and carbon-beam control group).

when irradiated cells were treated with the CpG-ODN, Bax expression was significantly downregulated (Fig. 6B), Bcl-2 expression was substantially upregulated (Fig. 6C), the ratio of Bax/Bcl-2 proteins markedly decreased (Fig. 6D), caspase-3 expression was significantly decreased, and the amount of cleaved caspase-3 was reduced to very low levels (Fig. 6E and Fig. 6F). These results suggested that the CpG-ODN regulated the expression of apoptosisrelated proteins and inhibited cellular apoptosis. 


\section{Discussion}

Tumor therapy with high-LET heavy ion irradiation has been widely used in the clinical setting, and residency on the space station has become a reality. However, due to quality and different physical characteristics, high-LET heavy ion radiation exposure poses a greater danger than low-LET radiation to normal tissue. High-LET heavy ion irradiation induces immunosuppression that increases the risk of opportunistic infections during radiotherapy and space exploration. Agents to reduce the damage induced by heavy ion irradiation are required to enhance efficiency during cancer radiotherapy and improve reliable risk estimates for space radiation. The macrophage cell line RAW264.7 represents a primary immune cell line [21]. TLR9 is highly expressed in the intracellular compartments of these cells. The only known ligand and agonist of TLR9 is a CpG-ODN, which may induce macrophage activation and proliferation $[22,23]$. In the present study, we used the mouse macrophage cell line RAW 264.7 to assess the protective effect of a CpG-ODN against highLET carbon-beam irradiation-induced damage, and parallel experiments were performed with low-LET $\gamma$-ray irradiation.

First, cell death was measured by PI/DAPI double staining. The CpG-ODN significantly reduced cell death after $\gamma$-ray and carbon-beam irradiation. For $\gamma$-ray radiation, the $\mathrm{LD}_{50}$ value was increased from $5.91 \mathrm{~Gy}$ to $6.83 \mathrm{~Gy}$, and the DMF value was 1.16. For carbon-beam radiation, the $\mathrm{LD}_{50}$ value was increased from $3.03 \mathrm{~Gy}$ to $4.35 \mathrm{~Gy}$, and the DMF value was 1.44. Second, the survival fraction was determined by colony-formation assays. The corresponding survival curve showed a shoulder region that is due to sub-lethal damage repair, whereas the change in the exponential region of the curve is due to the direct action of the radiation [1, 17]. Our results showed that when irradiated cells were treated with the CpG-ODN, survival was significantly increased. For $\gamma$-ray radiation, the shoulder region and the exponential part of the survival curve were altered by CpG-ODN treatment. For carbon-beam radiation, although the shoulder region was much narrower and the slope of the exponential region was much steeper than for $\gamma$-ray radiation, the CpG-ODN altered the shoulder region and the slope of the exponential region of the survival curve. These results suggested that the CpGODN enhanced cell survival after $\gamma$-ray and carbon-beam irradiation. We speculate that the CpG-ODN likely exerted a protective response against the direct effects induced by radiation to reduce and repair DNA damage rather than scavenging free radicals.

It was well known that DNA damage is the most serious threat to cells because it results in the loss or rearrangement of genetic information, eventually leading to cell death [19]. To further demonstrate the previously mentioned speculation, the degree of DNA damage was evaluated by comet assays. The study results showed that considerably shorter and narrower comet tails were observed in irradiated cells with CpG-ODN treatment compared with irradiated control cells, suggesting that the CpG-ODN alleviated the effect of DNA damage, which might be related to DNA damage repair after $\gamma$-ray and carbon-beam irradiation. In addition, the repair of damaged DNA also typically depends on DNA synthesis. $\mathrm{G}_{2} / \mathrm{M}$ phase of the cell cycle is a key part of this process and is tightly correlated with the radiosensitivity of the cells [24, 25]. Normal mammalian cells exposed to radiation were heavily damaged and characteristically delayed transit from $\mathrm{G}_{2}$ to $\mathrm{M}$ phase [26]. Although carbon-beam irradiation caused a higher relative $\mathrm{G}_{2} / \mathrm{M}$ phase arrest than $\gamma$-ray irradiation, the CpG-ODN significantly ameliorated $\mathrm{G}_{2} / \mathrm{M}$ phase arrest after both $\gamma$-ray and carbon-beam irradiation and correlated with a strong increase in the $G_{0} / G_{1}$ phase cell population. The $G_{0} / G_{1}$ phase is called the 'prophase' of cell division and is a stage in which rRNA, mRNA, tRNA and ribosomes are produced and heparin is synthesized [27]. These results not only confirmed that the CpGODN had the potential to enhance DNA repair but also suggested that the CpG-ODN helped irradiated cells proceed with improper cell division after $\gamma$-ray and carbon-beam irradiation.

Although the reason is not fully understood, apoptosis is the main mechanism of cell death after irradiation. The Bcl-2 family proteins are involved in the initiation phase of apoptosis, which represents a critical checkpoint, and act upstream of irreversible steps of cellular damage. Of the Bcl-2 family proteins, Bax causes the permeabilization of the 
mitochondria and release of apoptotic molecules, relocating cytochrome $c$ into the cytosol. Bcl-2 prevents Bax from initiating the permeabilization of the mitochondria. The balance between these two proteins determines how cells respond to apoptotic or survival signals [28]. Thus, the ratio of $\mathrm{Bax} / \mathrm{Bcl}-2$ is considered to be one of the major markers of apoptosis. Our results showed that when irradiated cells were treated with a CpG-ODN, Bax expression was upregulated, $\mathrm{Bcl}-2$ expression was downregulated, and the ratio of $\mathrm{Bax} / \mathrm{Bcl}-2$ was increased. These results indicated that Bcl-2 family proteins made a significant contribution to the inhibition of apoptosis by the CpG-ODN after $\gamma$-ray and carbon-beam irradiation. Furthermore, a decrease in the ratio of Bax/Bcl-2 reduced the release of cytochrome $c$ from the mitochondria into the cytosol and inhibited the activation of caspase family proteins [29]. The caspase family is responsible for the execution phase of apoptosis [30], and caspase-3 plays a central role in this process. Once activated, caspase- 3 rapidly induces the cleavage of poly ADP-ribose polymerase (PARP) and forms cleaved caspase-3, which in turn leads to the degradation of DNA into nucleosomal fragments [31]. Our results showed that CpGODN treatment led to a low level of caspase-3 expression and the disappearance of cleaved caspase- 3 after irradiation, suggesting that caspase- 3 activation was inhibited. These results confirmed that the CpG-ODN inhibited apoptosis after $\gamma$-ray and carbon-beam irradiation.

In conclusion, this study demonstrated that a CpG-ODN had protective effects against RAW264.7 cell damage induced by $\gamma$-ray and carbon-beam irradiation. The results showed that the CpG-ODN reduced cell death, enhanced cell survival, alleviated DNA damage, promoted cell-cycle progression and inhibited apoptosis after $\gamma$-ray and carbon-beam irradiation. We speculated that CpG-ODNs might be useful as a potential agent to protect cells from high-LET heavy ion irradiation.

Because this is the first time results of this type have been shown, the investigation described here could facilitate the design of strategies to focus on the protective effects of CpG-ODNs on irradiated cells. In further studies, we will assess the effect of CpG-ODNs on carcinogenesis, mutagenesis and chromosomal aberrations after irradiation.

\section{Acknowledgements}

The authors are grateful to the staff of the National Laboratory of Heavy Ion Accelerator (Lanzhou, China) for supplying the ion run. The work was supported by the National Natural Science Foundation of China (No. 31370840 and No. 81472911), Shanghai Natural Science found(14ZR1449200) and Shanghai Science and Technology Committee (124119b1900).

\section{Disclosure Statement}

The authors report no conflicts of interest. The authors are responsible for the content of this manuscript.

\section{References}

1 Guangming Z, Tetsuya K, Yoshiya F, Mizuho A, Ryoichi H, Koichi A, Hisao I: Protective effects of melatonin against low- and high- LET irradiation. J Radiat Res 2006;47:175-181.

- 2 Schmid TE, Dollinger G, Beisker W, Hable V, Greubel C, Auer S, Mittag A, Tarnok A, Friedl AA, Molls M, Roper B: Differences in the kinetics of gamma-H2AX fluorescence decay after exposure to low and high LET radiation. Int J Radiat Biol 2010;86:682-691.

-3 Li Q Dai Z, Yan Z, Jin X, Liu X, Xiao G: Heavy-ion conformal irradiation in the shallow-seated tumor therapy terminal at HIRFL. Med Biol Eng Comput 2007;45:1037-1043.

-4 Gong L, Jin X, Li Q Liu J, An L: Heavy Ion Beams Induce Survivin Expression in Human Hepatoma SMMC7721 Cells More Effectively than X-rays. Acta Biochim Biophys Sin 2007;39:575-582. 
5 Pecaut MJ, Dutta-Roy R, Smith AL, Jones TA, Nelson GA, Gridley DS: Acute effects of iron-particle radiation on immunity. Part I: Population distributions. Radiat Res 2006;165:68-77.

6 Sellami L, Lacombe S, Hunting D, Wagner RJ, Huels MA: Novel apparatus to measure hyperthermal heavy ion damage to DNA: strand breaks, base loss, and fragmentation. Rev Sci Instrum 2007;78:085111.

7 Gridley DS, Pecaut MJ, Nelson GA: Total-body irradiation with high-LET particles: acute and chronic effects on the immune system. Am J Physiol Regul Integr Comp Physiol 2002;282:R677-688.

$>8$ Krieg AM: CpG motifs in bacterial DNA and their immune effects. Annu Rev Immunol 2002;20:709-760.

-9 Kawai T, Akira S: TLR signaling. Semin Immunol 2007;19:24-32.

10 Kawai T, Akira S: TLR signaling. Cell Death Differ 2006;13:816-825.

$\checkmark 11$ Kawai T, Akira S: The role of pattern-recognition receptors in innate immunity: update on Toll-like receptors. Nat Immunol 2010;11:373-384.

-12 Sohn WJ, Lee KW, Choi SY, Chung E, Lee Y, Kim TY, Lee SK, Choe YK, Lee JH, Kim DS, Kwon HJ: CpGoligodeoxynucleotide protects immune cells from gamma-irradiation-induced cell death. Mol Immunol 2006;43:1163-1171.

13 Zhang C, Lin J, Cui J, Li B, Liu C, Wang J, Gao F, Cai J: Radioprotection of Bone Marrow Hematopoiesis by CpG-oligodeoxynucleotides Administered to Mice after Total-body Irradiation. J Radiat Res 2011;52:828833.

14 Zhang C, Ni J, Li BL, Gao F, Liu H, Liu W, Huang YJ, Cai JM: CpG-Oligodeoxynucleotide Treatment Protects against Ionizing Radiation-Induced Intestine Injury. PLoS One 2013;8:e66586.

15 Zhang C, Ni J, Gao F, Sun D, Zhou CF, Cheng Y, Cai JM, Li BL: The mechansim for the ameliorative effect of CpG-oligodeoxynucleotides on bone marrow hemopoiesis radiation injury. Basic Clin Pharmacol 2011;109:11-16.

16 Jurk M, Schulte B, Kritzler A, Noll B, Uhlmann E, Wader T, Schetter C, Krieg AM, Vollmer J: C-Class CpG ODN: sequence requirements and characterization of immunostimulatory activities on mRNA level. Immunobiology 2004;209:141-154.

17 Hall EJ, Giaccia AJ: Radiobiology for the Radiobiologist. Philadelphia, Lippincott Williams \& Wilkins, 2006.

18 Wang SC, Chung JG, Chen CH, Chen SC: 2- and 4-Aminobiphenyls induce oxidative DNA damage in human hepatoma (Hep G2) cells via different mechanisms. Mutat Res 2006;593:9-21.

19 Chen SC, Kao CM, Huang MH, Shih MK, Chen YL, Huang SP, Liu TZ: Assessment of genotoxicity of benzidine and its structural analogues to human lymphocytes using comet assay. Toxicol Sci 2003;72:283-288.

20 Tasyriq M, Najmuldeen IA, In LL, Mohamad K, Awang K, Hasima N: 7alpha-Hydroxy-beta-Sitosterol from Chisocheton tomentosus Induces Apoptosis via Dysregulation of Cellular Bax/Bcl-2 Ratio and Cell Cycle Arrest by Downregulating ERK1/2 Activation. Evid Based Complement Alternat Med 2012;2012:765316.

-21 Nishanth RP, Jyotsna RG, Schlager JJ, Hussain SM, Reddanna P: Inflammatory responses of RAW 264.7 macrophages upon exposure to nanoparticles: role of ROS-NFkappaB signaling pathway. Nanotoxicology 2011;5:502-516.

22 Takeshita S, Takeshita F, Haddad DE, Ishii KJ, Klinman DM: CpG oligodeoxynucleotides induce murine macrophages to up-regulate chemokine mRNA expression. Cell Immunol 2000;206:101-106.

-23 Utaisincharoen P, Anuntagool N, Chaisuriya P, Pichyangkul S, Sirisinha S: CpG ODN activates NO and iNOS production in mouse macrophage cell line (RAW 264 - 7). Clin Exp Immunol 2002;128:467-473.

-24 Pantelias GE, Terzoudi GI: A standardized G2-assay for the prediction of individual radiosensitivity. Radiother Oncol 2011;101:28-34.

25 Landsverk KS, Patzke S, Rein ID, Stokke C, Lyng H, De Angelis PM, Stokke T: Three independent mechanisms for arrest in G2 after ionizing radiation. Cell Cycle 2011;10:819-829.

26 Hwang A, Muschel RJ: Radiation and the G2 phase of the cell cycle. Radiat Res 1998;150:S52-59.

27 Scholey JM, Brust-Mascher I, Mogilner A: Cell division. Nature 2003;422:746-752.

28 Gross A, McDonnell JM, Korsmeyer SJ: BCL-2 family members and the mitochondria in apoptosis. Genes Dev 1999;13:1899-1911.

29 Ji BC, Hsu WH, Yang JS, Hsia TC, Lu CC, Chiang JH, Yang JL, Lin CH, Lin JJ, Suen LJ, Gibson Wood W, Chung JG: Gallic acid induces apoptosis via caspase-3 and mitochondrion-dependent pathways in vitro and suppresses lung xenograft tumor growth in vivo. J Agric Food Chem 2009;57:7596-7604.

30 Cohen GM: Caspases: the executioners of apoptosis. Biochem J 1997;326:1-16.

-31 Zhang Y, Jiang Q, Wang N, Dai B, Chen Y, He L: Effects of taspine on proliferation and apoptosis by regulating caspase-3 expression and the ratio of Bax/Bcl-2 in A431 cells. Phytother Res 2011;25:357-364. 